\title{
The contribution of UK farm assurance schemes towards desirable environmental policy outcomes
}

\author{
Kathy A. Lewis*, Andrew Green, John Tzilivakis and Douglas J. Warner \\ Agriculture and Environment Research Unit, School of Life Sciences, University of Hertfordshire, UK
}

\begin{abstract}
This study sought to evaluate the content of a range of UK primary production assurance schemes and their potential to support selected desirable agri-environmental policy outcomes. The schemes reviewed included those that fall under the Assured Food Standards umbrella plus eligible UK equivalents and examples of retailer and supplementary schemes. The assessment was based on scheme documentation (2008/2009), associated published literature and historical comment. The analysis showed that assurance schemes, generally, do not meet all the desired policy outcomes but this should not necessarily be expected or sought. However, such schemes are ideally placed to help the industry respond to changing demands, by changing or raising the scheme standards.
\end{abstract}

Keywords: eco-labelling; environmental policy; farm assurance schemes; farming standards; integrated production

\section{Introduction}

The UK Government, like that of many other countries, has to deliver on a number of interacting and sometimes contradictory environmental policy goals, many of which inevitably impact on agriculture. Consequently, there is increasing pressure to improve farming practices to ensure a more sustainable agricultural industry (Lewis et al., 2008). Policy makers and regulators are now exploring a variety of mechanisms by which this goal might be achieved, and in doing so make a contribution to the government's policy objectives on, for example, climate change and water quality, as well as animal health and welfare and a wide variety of societal issues. The use of farm assurance schemes is one of several methods being considered.

Farm assurance schemes in the UK have been established in order to provide, among other things, consumers with an increased level of confidence that crop and/or livestock products have been produced in a way that meets certain standards, be they related to environmental issues, animal welfare or food safety. As such, they jointly play a 'regulatory' role (by ensuring that the prescribed standards are being met) and a 'marketing' role (by communicating that fact to the consumer to promote the product). Each scheme operates according to defined processes and principles that include a set of standards expressed as conformance points (CPs) against which the actions of primary producers are subsequently judged by independent assessors. The term 'conformance' rather than 'performance' has been used here as in each scheme there are requirements that are not necessarily related to the way the food is produced but are administrative, for example, the use of scheme labels and branding. Membership of a scheme is voluntary and farmers pay a joining fee and annual subscription that covers the scheme administration and inspection costs. In order to gain scheme certification, members must comply with scheme operational rules and meet the standards as prescribed. These schemes effectively act as mechanisms for ensuring that certain desirable or undesirable farming practices are either adopted or abandoned, as appropriate, considering the schemes' objectives. Assurance schemes do not all have the same objectives. While some are focused on food safety, others specifically address animal welfare issues or offer assurance that the farmer used environmentally sound production methods. 
The UK is not unique in using assurance schemes, but their adoption varies considerably from country to country and marked differences are evident even within the European Union (EU). There are many influencing factors including consumer confidence in food, the strictness of national regulation, and the differing values and living standards of consumers. For example, in France there are schemes with an environmental emphasis for specific crops such as tomatoes (Tomato De France), top fruit (GRECETA) and vegetables (Ceafl of Val de Saire), and quality-orientated schemes include Quali'Terre, which is operated by the Chambres d'Agriculture. Another example is the Swedish food quality scheme 'Seal Farm'. This scheme began in 1995 and covers around 85,000ha most of which are cereals. However, there are some countries where assurance schemes have not been widely implemented. In Denmark, for example, the idea of developing a special environmental food label was considered, that is, Green $\varnothing$ to complement the established Red $\varnothing$ organic label (Lewis et al., 2008). However, the draft standards developed encompassed a very large proportion of all Danish production and so its produce would not have attracted a market premium. Consequently, the idea was dropped (Levidow, 2000). Similarly, Finland has stringent regulations governing food production and traceability that are seen as being sufficiently rigorous to simultaneously safeguard the environment and, as a result, Finland has not found a role for assurance schemes. There are also EU-wide and global schemes, for example, GlobalGAP. GlobalGAP is a private sector body that sets voluntary standards for the certification of agricultural products around the world. The aim is to establish a single common standard capable of being applied to the whole of global agriculture. When considering the approach adopted by the UK compared to other countries, one obvious difference is that the UK appears to have a strong desire to minimize regulation and encourage the industry to adopt higher standards voluntarily. As a result, the UK has more examples of assurance schemes in operation than many other countries.

Primary food production in the UK is currently influenced by a plethora of different assurance initiatives. Over 78,000 UK farmers were members of Assured Food Standards (AFS) schemes during 2007, accounting for between 65 and 90 per cent of output in the main commodity sectors (KirkWilson, 2008). Membership of an appropriate scheme is usually required before produce can be sold. Such schemes could, therefore, potentially offer a vehicle for delivering significant policy benefits. They also offer practical advantages as they are already operational, have inspection systems in place and are sufficiently flexible to allow different issues and objectives to be prioritized. However, these schemes were not created to deliver national policy and their objectives and priorities may not match those of the government. Consequently, they may not deliver policy objectives and, indeed, they may have no desire to do so. Therefore, if assurance scheme membership is to be adopted as a surrogate for additional governmental intervention, then it is important to understand both where synergies exist and where there are gaps in coverage. This paper describes and reports on a study based on the main UK primary production assurance schemes, which sought to identify the potential contribution such schemes could make towards achieving a range of desired agri-environmental policy outcomes. The methodology adopted sought to identify the key areas covered by each scheme by analysing scheme standards and in so doing identify their strengths and weaknesses in terms of supporting policy.

\section{Approach and methodology}

The study adopted a three-part approach. Firstly, a scoping exercise was undertaken to identify the schemes which would be included in the study and the range of government policy objectives against which the schemes would be evaluated. Appropriate environmental policy objectives were identified in consultation with government officials.

Secondly, the format and the stringency of the operational aspects of each scheme were evaluated in order to determine the likelihood of any identified benefits being realized. This part of the study utilized a standard list of evaluation points and pre-defined questions designed to encompass the 
full range of relevant operational aspects, including the approach to environmental risk management and mitigation, the scheme's transparency to consumers, how the inspection process was managed (e.g. its flexibility, the frequency of visits, desk-based or site-based and stringency) and assessment (e.g. procedures, enforcement and penalties).

Finally, the environmental content of each scheme was identified to see if there was potential to contribute towards the identified agri-environmental policy outcomes. This was achieved via a detailed analysis of the documented standards of each scheme, together with the guidance notes used by the scheme assessors. It should be noted that this analysis was not equivalent to an environmental impact assessment and did not seek to quantify environmental outcomes. It only considered the environmental issues that were addressed and highlighted the main focus of each of the schemes. The work was intended to provide an indication of coverage, and perhaps more importantly identify gaps for which other delivery mechanisms may be required.

The content analysis comprises two main steps. Firstly, a rudimentary count of the number of CPs and critical failure points (CFPs) within each scheme as a whole and contributing to each of the policy criteria was made. For the purposes of this study, CPs are defined as any assessment point within the scheme. These may be mandatory or just recommendations. CFPs are defined as mandatory CPs where non-compliance may result in non-certification. From a policy perspective, CFPs are important as any identified policy benefits are likely to be realized whereas there are no guarantees that recommendations will be adopted by sufficient scheme members to assure benefits are seen. However, from an assurance scheme point of view, including a number of recommendations may be desirable as it provides an incentive and direction for improvement.

Secondly, a scoring and weighting process was undertaken. For each scheme, each individual CP was considered regarding its potential contribution towards each policy outcome and awarded a weighting factor (0-5) chosen to reflect the 'directness' of the CP in addressing each outcome. This allowed the 'significant and direct content' to be assessed by considering just the quantity of CPs 'directly' addressing each policy issue (i.e. those weighted 4 or 5). Such an exercise is undoubtedly subjective and in order to ensure a fair and robust evaluation that was consistent across all the schemes, each was considered by at least three individual researchers with relevant broad experience using previously established weighting guidelines as shown below:

- Score of 4 or 5 where the CP directly influences the desired policy outcome, there is ample, well documented scientific evidence supporting the influence and compliance with the standard is verifiable.

- Score 3 or 4 where the CP directly influences the policy outcome to some extent and there is some documented evidence to support this.

- Score 2 or 3 where the contribution of the CP towards policy objectives is less significant and/or there is well-documented evidence to suggest that the standard will influence the desired policy outcome but it is via an indirect route.

- Score 1 where the CP 'may' offer some minor policy benefits and/or the link is tenuous and not well documented.

- Score 0 if the CP is not known to offer benefits for the policy outcome directly or indirectly.

In addition, 'spot checks' were undertaken by a fourth independent specialist researcher so as to confirm accuracy. Anomalies, such as significant differences in the scores allocated by different researchers, were addressed via debate and review. The findings and conclusions were based on the mean value of all weightings obtained. 
The approach to CFPs varies considerably from scheme to scheme. For some schemes all standards are mandatory while others include some recommendations. Nature's Choice takes a fundamentally different approach having a relatively few number of CFPs and compliance with these is mandatory in order to supply Tesco retail. The scheme also has 'Obligatory Control Points' and compliance with these is used to grade a producers' performance (i.e. gold, silver, bronze). Nature's Choice also includes some 'Standard Control Points', which are broadly equivalent to recommendations in other schemes.

This assessment process was based solely upon documented evidence and careful consideration of the wording of the standards. It is simply an assessment of the focus of the standard as prescribed. It is fully appreciated that there are many factors that affect the scheme quality, including, for example, the training, competence and strictness of inspectors and on-farm advice and guidance provided by the schemes. These issues have not been captured in this study. Some studies that have reviewed the impact and uptake of assurance schemes (e.g. Kirk-Wilson, 2008) have based many of their conclusions on one-to-one interviews. This approach was rejected for this study as a more systematic and analytical methodology was required.

\section{Results and discussion}

\section{Policy criteria}

Policy criteria selected were based on a variety of policy documents (Defra, 2002, 2003a, b, 2004, 2005, 2006a, b, 2007a, b) and agreed with government officials. These are given in Table 1.

\section{Table 1. Desired policy outcomes selected for the study}

\begin{tabular}{l|l}
\hline Objectives & Includes for example..... \\
\hline Air quality & Minimization of gaseous releases, odours, particulate matter etc. \\
\hline Water quality & $\begin{array}{l}\text { Minimization of surface and groundwater pollution from nitrates, pesticides, oils, } \\
\text { bacteria and other micro-organisms etc. }\end{array}$ \\
\hline Water efficiency & Optimal use of water for irrigation, livestock management and general farm use. \\
\hline Soil protection & $\begin{array}{l}\text { Minimization of soil structure damage and erosion, maintenance of fertility, } \\
\text { protection from contamination. }\end{array}$ \\
\hline Biodiversity & Conservation and enhancement activities of habitats and wildlife food sources. \\
\hline Climate change & Energy efficiency, carbon footprinting and use of renewable energy. \\
\hline Resource management & $\begin{array}{l}\text { Waste management processes, reuse and recycling, minimization/optimal use } \\
\text { of farm inputs and efficiency auditing. }\end{array}$ \\
\hline
\end{tabular}

\section{Scheme Identification}

A total of 14 schemes covering 33 different sets of standards were included in the study. While there are other established schemes in the UK, those listed were selected based on the assumption that the larger the scheme in terms of its membership or farmed area, the greater the potential for delivering the desired policy outcomes. The exception to this was the inclusion of LEAF Marque and Jordan's. No other criterion for selection was used. In order to consider how the mainstream schemes compared with the smaller and more specialist schemes, the aforementioned schemes were also included. Only on-farm standards were considered. Any standards that applied to off-farm activities such as transportation were omitted. This was to ensure a more harmonized coverage as in some schemes off-farm activities were included and in other cases separate standards altogether exist. Table 2 summarizes the primary objectives of each scheme and provides brief details of uptake or coverage and scheme management. These were extracted from the schemes' public website pages (November 2008). 
Table 2 also shows that both size and coverage of the chosen schemes vary considerably. Generally, the cropping schemes put food quality, safety and traceability high on their list of objectives, whereas the livestock schemes appear to focus on ensuring high production standards and animal welfare. Environmental protection is given as a primary objective on the websites of several schemes. The two supplementary schemes (LEAF Marque and Jordan's Conservation Grade) are both very small with respect to the number of farms participating compared with the other schemes and, as such, may not be able to contribute significantly to the delivery of policy objectives.

Table 2. UK Primary Production Assurance Schemes selected for the study

\begin{tabular}{|c|c|c|}
\hline $\begin{array}{l}\text { Scheme } \\
\text { (reference) }\end{array}$ & Brief description & Objectives \\
\hline \multicolumn{3}{|c|}{ AFS (68,000 members: $65-95 \%$ UK production) } \\
\hline $\begin{array}{l}\text { Assured Produce } \\
(A P, 2008)\end{array}$ & $\begin{array}{l}\text { Fresh produce cropping - fruit, salads and } \\
\text { vegetables. } 3000 \text { members } \& \sim 80 \% \text { UK } \\
\text { market. Managed, developed and promoted } \\
\text { by AFS. Producer-led scheme. }\end{array}$ & $\begin{array}{ll}\text { - } & \text { Food safety, quality \& traceability } \\
\text { - } & \text { Affordability } \\
\text { - } & \text { Environmental care }\end{array}$ \\
\hline $\begin{array}{l}\text { Assured Combinable } \\
\text { Crops Scheme } \\
\text { (ACCS, 2008) }\end{array}$ & $\begin{array}{l}\text { Combinable crops \& sugar beet, } 2600 \\
\text { members, } 83 \% \text { UK market for combinable } \\
\text { crops and } \sim 30 \% \text { sugar beet. Managed, } \\
\text { developed and promoted by AFS. } \\
\text { Producer-led scheme. }\end{array}$ & - $\quad$ Food safety, quality \& traceability \\
\hline $\begin{array}{l}\text { Assured British Pigs } \\
(A B P, 2007)\end{array}$ & $\begin{array}{l}\text { Livestock, } 1200 \text { members, } 45 \% \text { industry. } \\
\text { Managed, developed and promoted by AFS. } \\
\text { Producer-led scheme. }\end{array}$ & - $\quad$ Food safety, quality \& traceability \\
\hline $\begin{array}{l}\text { Assured Chicken } \\
\text { Production } \\
\text { (ACP, 2007) }\end{array}$ & $\begin{array}{l}\text { Livestock, } 2000 \text { members, 95\% industry. } \\
\text { Managed, developed and promoted by AFS. } \\
\text { Producer-led scheme (sets of standards). }\end{array}$ & - $\quad$ Food safety, quality \& traceability \\
\hline $\begin{array}{l}\text { Assured Dairy Farms } \\
\text { (ADF, 2008) }\end{array}$ & $\begin{array}{l}\text { Livestock, } 13,500 \text { members, } 95 \% \\
\text { production. Managed, developed and } \\
\text { promoted by AFS. Producer-led scheme. }\end{array}$ & $\begin{array}{ll}\text { - } & \text { Food safety, quality \& traceability } \\
\text { - } & \text { Animal welfare } \\
\text { - } & \text { Environmental care }\end{array}$ \\
\hline $\begin{array}{l}\text { Assured British Meat } \\
\text { (ABM, 2008) }\end{array}$ & $\begin{array}{l}\text { Livestock, } 2600 \text { members, } 8000+\text { outlets. } \\
\text { Managed, developed and promoted by AFS. } \\
\text { Producer-led scheme. }\end{array}$ & $\begin{array}{ll}\text { - } & \text { Food safety, quality \& traceability } \\
\text { - } & \text { Animal welfare } \\
\text { - } & \text { Environmental care }\end{array}$ \\
\hline \multicolumn{3}{|c|}{ AFS equivalent schemes } \\
\hline $\begin{array}{l}\text { Farm Assured Welsh } \\
\text { Livestock } \\
\text { (FAWL, 2008) }\end{array}$ & $\begin{array}{l}\text { Livestock, } 7400 \text { producers, } 60 \% \text { lamb and } \\
70 \% \text { beef. Managed by Welsh Lamb } \\
\text { and Beef Producers Ltd. Producer-led } \\
\text { scheme. }\end{array}$ & $\begin{array}{ll}\text { - } & \text { Animal welfare } \\
\text { - } & \text { High production standards }\end{array}$ \\
\hline $\begin{array}{l}\text { Northern Ireland } \\
\text { Farm Quality } \\
\text { (NIFQA, 2008) }\end{array}$ & $\begin{array}{l}\text { Livestock, } 1100 \text { producers, } 87 \% \text { prime beef, } \\
67 \% \text { cow beef, } 67 \% \text { lamb. Managed by the } \\
\text { Livestock and Meat Commission for } \\
\text { Northern Ireland. Producer-led scheme. }\end{array}$ & $\begin{array}{ll}\text { - } & \text { Food safety, quality \& traceability } \\
\text { - } & \text { Animal welfare } \\
\text { - } & \text { Environmental care }\end{array}$ \\
\hline $\begin{array}{l}\text { Quality Meat } \\
\text { Scotland } \\
\text { (QMS, 2007) }\end{array}$ & $\begin{array}{l}\text { Haulage, Feed and Livestock. 10,750 } \\
\text { producers, } 93 \% \text { cattle, } 87 \% \text { sheep, } 99 \% \text { pig } \\
\text { producers. Managed by Quality Meat } \\
\text { Scotland, a non-departmental public body } \\
\text { sponsored by the Scottish Government. } \\
\text { Producer-led scheme ( } 4 \text { sets of standards). }\end{array}$ & $\begin{array}{ll} & \text { Animal welfare } \\
\text { - } & \text { High production standards }\end{array}$ \\
\hline $\begin{array}{l}\text { Genesis Quality } \\
\text { Assurance } \\
\text { (Genesis, 2007) }\end{array}$ & $\begin{array}{l}\text { Livestock and arable cropping } 4000 \\
\text { producers - } 850 \text { pig, } 1780 \text { beef, } 1800 \\
\text { cropping. Managed by Genesis Quality } \\
\text { Assurance Ltd. Producer-led scheme (3 sets } \\
\text { of standards). }\end{array}$ & $\begin{array}{ll}\text { - } & \text { Food safety, quality \& traceability } \\
\text { - } & \text { High production standards } \\
\text { - } & \text { Legal compliance } \\
\text { - } & \text { Animal welfare } \\
\text { - } & \text { Environmental care }\end{array}$ \\
\hline
\end{tabular}




\begin{tabular}{|c|c|c|}
\hline $\begin{array}{l}\text { GlobalGap } \\
\text { (GlobalGap, 2007) }\end{array}$ & $\begin{array}{l}\text { All farms, cropping and livestock } 80,000+ \\
\text { producers across all sectors in } 80+\text { different } \\
\text { countries. A private sector body. Retailer/ } \\
\text { shippers-led scheme ( } 9 \text { modules/sets of } \\
\text { standards). }\end{array}$ & $\begin{array}{ll}\text { - } & \text { Food safety and quality } \\
\text { - } & \text { High production standards } \\
\text { - } & \text { Occupational health } \\
\text { - } & \text { Animal welfare } \\
\text { - } & \text { Environmental care }\end{array}$ \\
\hline $\begin{array}{l}\text { Nature's Choice } \\
\text { (Tesco, 2006, 2007) }\end{array}$ & $\begin{array}{l}\text { Cropping, 15,400 registered farms, } 9350 \\
\text { certified farms, 507,530ha total. Managed, } \\
\text { developed and promoted by Tesco Ltd. } \\
\text { Retailer-led scheme. }\end{array}$ & $\begin{array}{ll}\text { - } & \text { Food quality and safety } \\
\text { - } & \text { Sustainable farming } \\
\text { - } & \text { Environmental care } \\
\text { - } & \text { Occupational health }\end{array}$ \\
\hline \multicolumn{3}{|c|}{ Supplementary schemes } \\
\hline $\begin{array}{l}\text { Leaf Marque } \\
\text { (LEAF, 2007, 2008) }\end{array}$ & $\begin{array}{l}\text { Cropping, } 307 \text { registered farms (UK), } \\
\text { 119,000ha. Managed, developed and } \\
\text { promoted by LEAF, a charitable body. }\end{array}$ & $\begin{array}{ll}\text { - } & \text { Environmental care and IFM } \\
\text { - } & \text { Food safety and quality }\end{array}$ \\
\hline $\begin{array}{l}\text { Jordan's } \\
\text { Conservation Grade } \\
(\text { GCGP, 2007a, b) }\end{array}$ & $\begin{array}{l}\text { Cropping. } 53 \text { farms. Managed, developed } \\
\text { and promoted by The Guild of Conservation } \\
\text { Grade Producers. Producer-led scheme. }\end{array}$ & $\begin{array}{l}\text { - } \quad \text { High production standards } \\
\text { - } \quad \text { Biodiversity } \\
\text { - } \quad \text { Increased market share }\end{array}$ \\
\hline
\end{tabular}

\section{Operational aspects}

The schemes selected encompass a range of approaches to scheme management and while their general structure is broadly similar there are considerable differences in the fine details regarding, for example, the approaches to risk management, the transparency of the scheme and the inspection process.

The formal documentation of both Assured Produce (AP, 2008) and Assured Combinable Crops (ACCS, 2008) declare a systematic approach to risk assessment particularly with respect to food safety. In both cases, the Hazard Analysis and Critical Control Points (Bauman, 1990) approach is adopted. In other schemes, the documentation does not explicitly require a formalized approach but tends to incorporate risk management through less systematic processes such as site-specific management plans. Both LEAF Marque and Nature's Choice place considerable emphasis on such plans as they offer flexibility and can be developed to encompass specific issues important to the farm. However, the ability of such plans to mitigate risks and help deliver both the scheme and governmental policy objectives will depend entirely on their content and application. In all the schemes where management plans were required, little guidance was available regarding their format and content and, as a consequence, there is scope for variation and it is up to the assessor to decide if the plan is fit for purpose. It should also be remembered that just having a plan does not, in itself, guarantee its application or success. In some cases, the actual wording of the relevant CP and the associated assessor notes only required the plan to be available and there was little indication that evidence of application was sought.

For all schemes, except for those that are commercially sensitive (e.g. Nature's Choice and Jordan's Conservation Grade), the full standards can be freely downloaded from a publicly accessible website. However, the provision of documentation is not necessarily the same as providing information that makes it clear to the consumer what the standards actually mean and how they are enforced. While the scheme holders did provide general consumer-orientated information there was little explaining the processes and operating procedures of the schemes in layman's terms. Standard enforcement procedures were, if anything, even less transparent due to the technical nature of these specific regulations. It is important to remember that the availability of information is not an indicator of the extent to which consumers are actually aware of the content or purpose of a standard. This is dependent on the quality and suitability of the information and if the information is actually being accessed. 
The inspection process, and the strictness and competence of the assessor are critical to the quality of any scheme. In all cases, the schemes stated that this process would include investigating farm documentation and undertaking a site inspection. Most of the schemes require an inspection on an annual basis. However, there were subtle differences in the way this requirement was expressed. Some simply stated that an annual inspection is required (e.g. Genesis) while others (e.g. Assured Produce) stated that an inspection should take place at least once per year implying that the interval could be shorter. Others state that an inspection should take place once in every scheme year (LEAF Marque) or every crop cycle (Assured Combinable Crops) and sometimes maximum/minimum times between inspections were also given. Different approaches are adopted by Nature's Choice and Jordan's Conservation Grade. Members of Nature's Choice generally undergo an annual inspection. However, if they achieve the highest possible performance grade (Gold Status) audits move to a 24month cycle while that grade is retained. In the case of Jordan's, the scheme has two parts. Firstly, similar to other schemes, the set of standards and conformance is assessed annually. Secondly, the grower must commit at least 10 per cent of the farmed area to a range of managed wildlife habitats and a farm-specific habitat assessment is carried out every five years. Perhaps equally as important as the scheduled inspections were the use of unscheduled checks. Most of the schemes did include spot checks but the frequency and farm selection process varied. Some schemes selected farms completely at random while others based selection on previous breaches or complaints.

All the schemes inevitably allowed for a certain amount of discretion when assessing compliance with specific requirements since it is often down to the skill and expert judgement of the assessor on the ground. This flexibility could be seen as either a strength or weakness for both the scheme and for delivering desirable policy outcomes. There is no such thing as the standard farm, and so they cannot be assessed in the same way as, for example, a clearly defined industrial process. Instead, it must be possible to apply the rules to a wide variety of different farm situations and so a certain amount of flexibility is essential. However, too much flexibility could result in inconsistencies in the standards achieved.

In summary, while there were differences in the operational detail across the schemes, there was no reason to believe that the schemes would not be a valuable vehicle for delivering policy outcomes. However, realizing the full benefits would depend upon the ability of the assessors on the ground. The UK farm assurance industry invests significantly in assessor training, and this, together with suitable quality control systems, should ensure that any policy benefits that such schemes could deliver are delivered. The only doubt that exists is what can reasonably be achieved in the amount of time an assessor spends on any farm, which is, typically, just 2-4 hours and increasing it further would be costly and burdensome to the farm.

\section{Content analysis}

Figure 1 shows the total number of CPs within each scheme and the total number of CFPs. Across the schemes there are different types of assessment points and different 'levels' of standards. It can clearly be seen from Figure 1 that the number of CPs varies considerably from scheme to scheme, ranging from just 43 in Jordan's Conservation Grade to over 300 in the GlobalGap Poultry Standards.

Figure 2 shows the percentage of CPs relevant to environmental protection policy objectives and illustrates the broad variation across the schemes. All the schemes related to cropping enterprises have considerably greater proportions of environmental content than those related to livestock enterprises and this is largely a reflection of the CPs relating to good practice regarding chemical inputs such as fertilizers and pesticides. Of the cropping-related schemes, LEAF Marque clearly stands out, reflecting its primary objective of encouraging integrated farming and environmental protection. LEAF Marque is used in conjunction with another assurance scheme, such as Assured Produce, and as there appears to be little overlap in the standards the benefits of both schemes would be seen. 


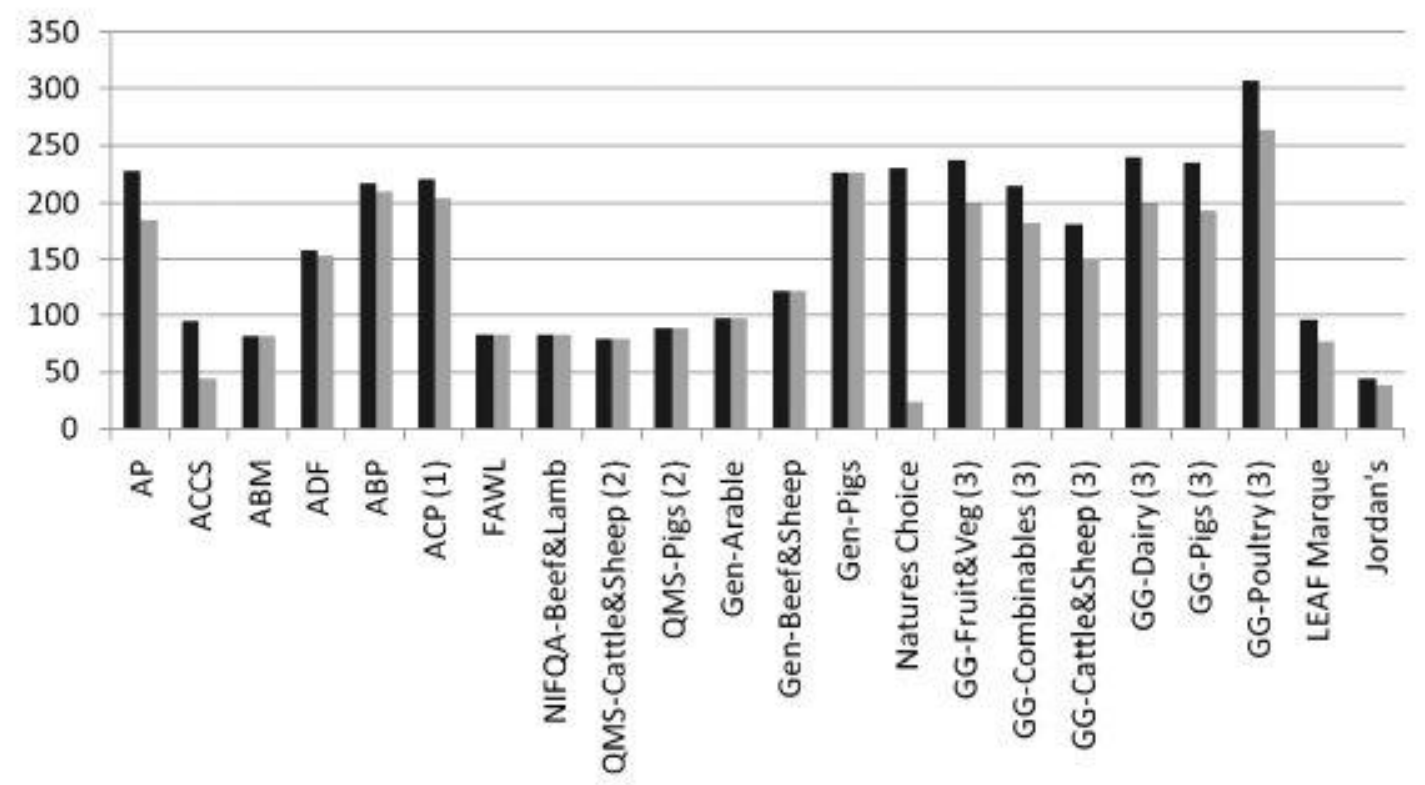

Total number of Conformance Points

Total number of Critical Failure Points

Figure 1. Scheme size by the number of CP

ADF - Assured Dairy Farms; ABP - Assured British Pigs; ACP - Assured Chicken Production; FAWL - Farm Assured Welsh Livestock; NIFQA - Northern Ireland Farm Quality Assurance; QMS - Quality Meat Scotland; Gen - Genesis; GG GlobalGap.

Notes: (1) Average across different production chains, (2) includes standards for feed and haulage, (3) includes baseline modules for all farms, crops and livestock as appropriate.

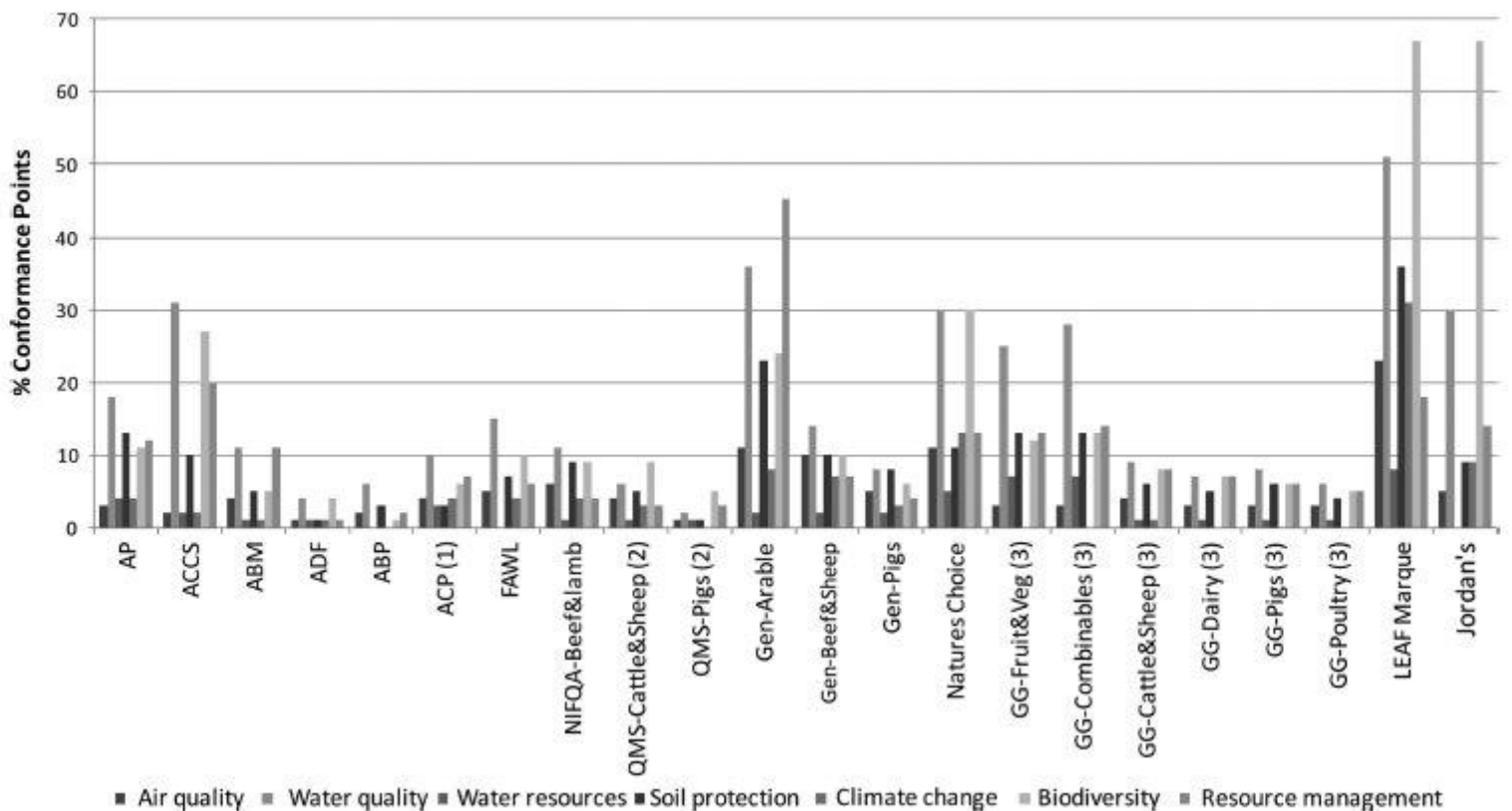

Figure 2. Total number of CPs addressing each policy criterion

Notes and key - see Figure 1. 
Jordan's Conservation Grade scheme is perhaps best compared with LEAF Marque. From Figure 2 it can be seen that it does not appear to do as well overall as LEAF Marque. Jordan's Conservation Grade has a very narrow focus of biodiversity protection and habitat management and it is only available to the relatively few growers who supply Jordan's Cereals. In addition, as the scheme is not based on a large number of CPs (see Figure 1), the findings are 'diluted' somewhat by the questions concerned with administrative requirements such as those addressing the growers' membership of other assurance schemes and the Guild. This issue of 'dilution' is relevant to all the schemes but the number of such CPs is similar from scheme to scheme and thus becomes less significant as size increases. However, assessment of content in the manner carried out in this study is not doing the Jordan's scheme justice. Designated wildlife habitats on the farm are assessed for quality and their impact on local wildlife by independent assessors from the British Naturalists' Association. The habitat assessment also considers how other habitats on the farm, such as hedgerows, those in and along waterbodies and nesting and roosting sites, are managed and maintained. In this way, actual outcomes are considered and not just farming practices. Consequently, Jordan's Conservation Grade scheme is the only scheme considered that seeks enhancement in terms of habitats and biodiversity going well beyond the basic protection from damage provided by other schemes. It is also operated alongside an AFS scheme and so farmers growing for Jordan's Cereals should be delivering significant benefits for biodiversity. However, as the scheme is only open to the relatively few growers who supply Jordan's Cereals (Table 2 ), policy benefits may be limited nationally.

At the opposite end of the scale, the AFS livestock schemes have very little environmental content; however, this is a reflection of the individual schemes' objectives that are primarily concerned with animal welfare and food safety. The data show that environmental protection is not greatly covered by the livestock schemes; however, as shown in Table 2 some of the livestock schemes do quote environmental protection as an objective on their public websites.

Another observation that can be made from Figure 2 and summarized in Table 3 is that while issues such as protecting water quality, biodiversity and soils have the greatest attention within the schemes, other policy criteria are neglected. Air quality protection is one example. While some schemes (e.g. GlobalGap, Assured Produce, LEAF Marque and Nature's Choice) do require energy efficiency planning and some of these also require regular equipment maintenance, little else is offered. A related issue that is very high on the political agenda and an important policy objective is that of climate change mitigation; however, specific content within the schemes such as carbon footprinting and utilization of renewable energies is absent. Another issue neglected is that of resource management. With respect to water, most of the cropping-related schemes do include CPs relating to best practice and efficiency of crop irrigation, but water management plans and irrigation scheduling have no priority. Most schemes require a waste management plan but go little beyond this to address, for example, the optimization of farm inputs and recycling. These gaps in content become more obvious in Figures 3 and 4. Figure 3 displays the total weighted value for each scheme and each policy objective. Figure 4 shows the total number of 'direct and significant' CPFs, that is, those that were awarded a weighting value of 5 or 4 . The weighted data (Figure 4) demonstrate that a considerable amount of the environmental content is a secondary benefit of other scheme objectives such as food safety, food quality and animal health and welfare. It also shows that the proportion of content that sets out to seriously tackle environmental issues is very limited in all but a few of the schemes considered in this study.

Table 3. Summary of environmental content for all CPs

\begin{tabular}{|c|c|c|c|c|c|c|c|}
\hline Scheme & Air quality & $\begin{array}{c}\text { Water } \\
\text { quality }\end{array}$ & $\begin{array}{c}\text { Water } \\
\text { resources }\end{array}$ & Soils & $\begin{array}{c}\text { Climate } \\
\text { change }\end{array}$ & Biodiversity & Resources \\
\hline
\end{tabular}




\begin{tabular}{|c|c|c|c|c|c|c|c|}
\hline AP & Low & Medium & Low & Medium & Low & Medium & Medium \\
\hline ACCS & Low & $\mathrm{HIGH}$ & Low & Low & Low & Medium & Medium \\
\hline ABM & Low & Low & Low & Low & Low & Low & Low \\
\hline ADF & Low & Low & Low & Low & Low & Low & Low \\
\hline ABP & Low & Low & Low & Low & Low & Low & Low \\
\hline ACP & Low & Low & Low & Low & Low & Low & Low \\
\hline FAWL & Low & Low & Low & Low & Low & Low & Low \\
\hline $\begin{array}{l}\text { NIFQAS- BEEF } \\
\& \text { LAMB }\end{array}$ & Low & Medium & Low & Low & Low & Low & Low \\
\hline $\begin{array}{l}\text { QMS Cattle \& } \\
\text { Sheep }\end{array}$ & Low & Low & Low & Low & Low & Low & Low \\
\hline QMS-Pigs & Low & Low & Low & Low & Low & Low & Low \\
\hline Gen-Arable & Medium & $\mathrm{HIGH}$ & Low & Medium & Low & Medium & Medium \\
\hline $\begin{array}{l}\text { Gen-Beef \& } \\
\text { Sheep }\end{array}$ & Low & Medium & Low & Low & Low & Low & Low \\
\hline Gen-Pigs & Low & Low & Low & Low & Low & Low & Low \\
\hline $\begin{array}{l}\text { Nature's } \\
\text { Choice }\end{array}$ & Medium & $\mathrm{HIGH}$ & Low & Medium & Medium & $\mathrm{HIGH}$ & Medium \\
\hline $\begin{array}{l}\text { GG-Fruit \& } \\
\text { Veg }\end{array}$ & Low & Medium & Low & Medium & Low & Medium & Medium \\
\hline $\begin{array}{l}\text { GG- } \\
\text { Combinables }\end{array}$ & Low & Medium & Low & Medium & Low & Low & Low \\
\hline $\begin{array}{l}\text { GG-Cattle \& } \\
\text { Sheep }\end{array}$ & Low & Low & Low & Low & Low & Low & Low \\
\hline GG-Dairy & Low & Low & Low & Low & Low & Low & Low \\
\hline GG-Pigs & Low & Low & Low & Low & Low & Low & Low \\
\hline GG-Poultry & Low & Low & Low & Low & Low & Low & Low \\
\hline LEAF Marque & Medium & $\mathrm{HIGH}$ & Low & $\mathrm{HIGH}$ & $\mathrm{HIGH}$ & $\mathrm{HIGH}$ & Medium \\
\hline Jordan's & Low & $\mathrm{HIGH}$ & Low & Low & Low & $\mathrm{HIGH}$ & Medium \\
\hline
\end{tabular}

Key: Low <10\% content; medium 10-30\% content; High > 30\% content. Bandings selected based on the overall distribution of scores. 


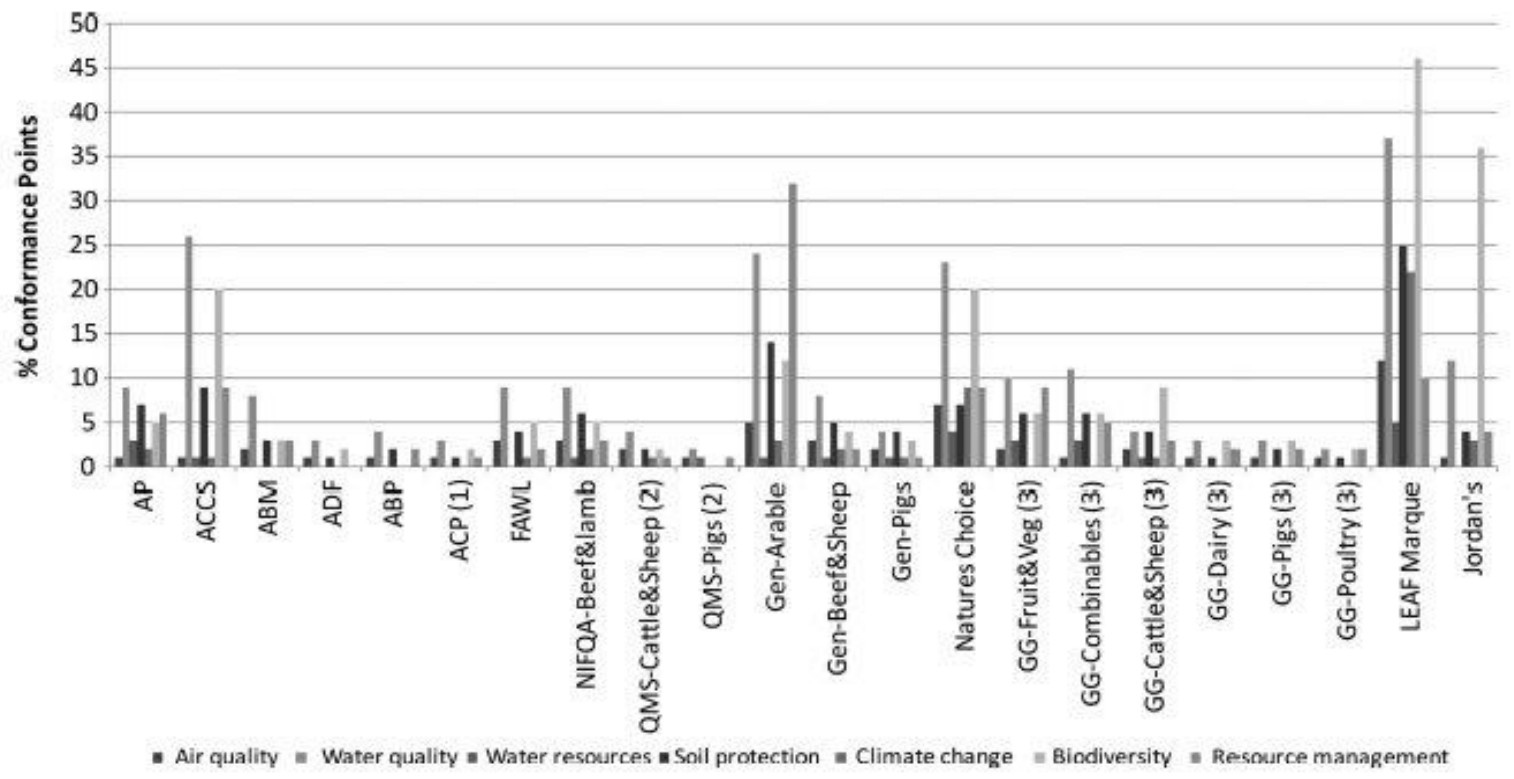

Figure 3. Total number of critical failure CPs addressing each policy criterion Notes and key - see Figure 1.

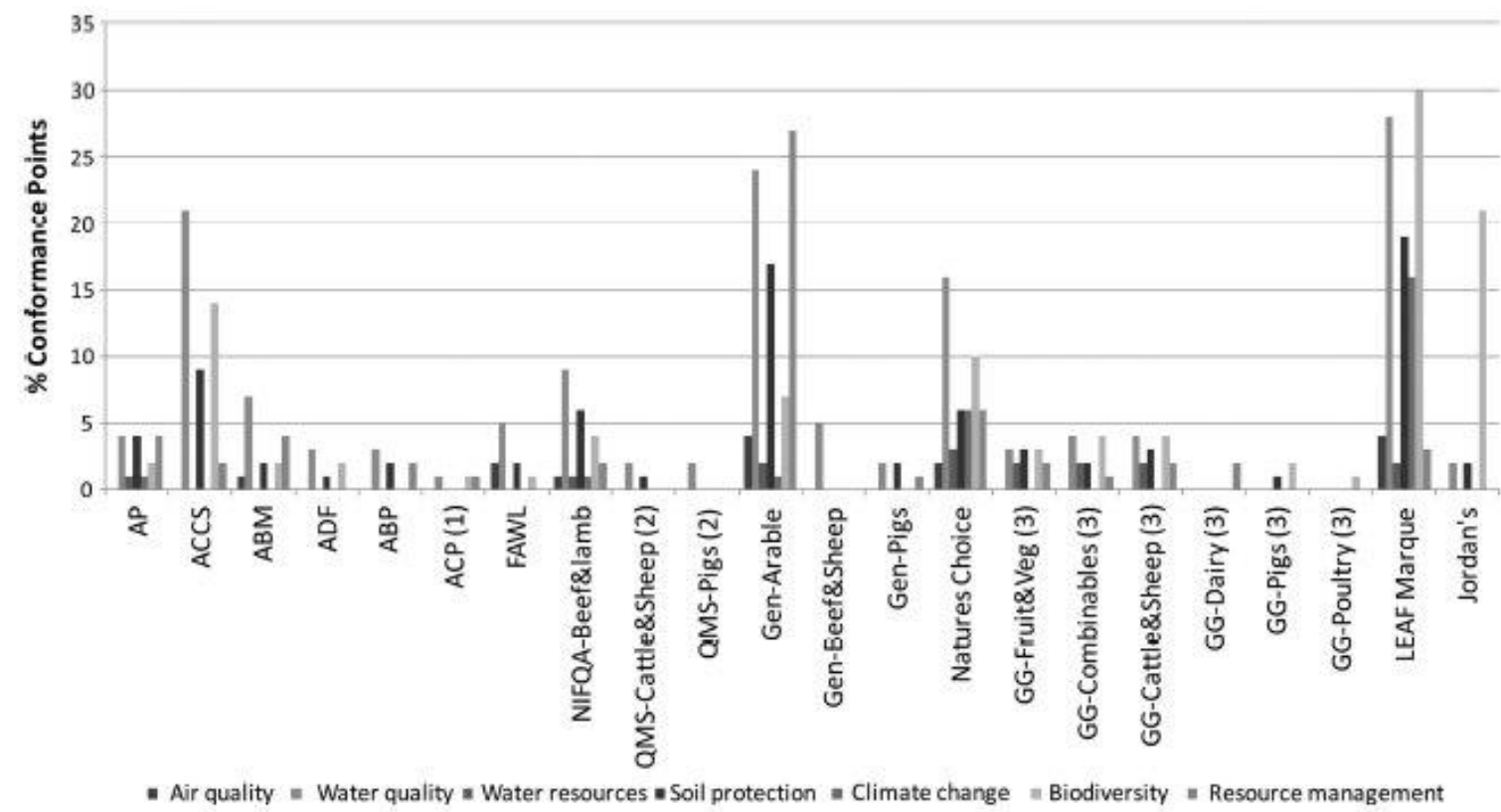

Figure 4. Total number of 'direct and significant' CPs addressing each policy criterion Notes and key - see Figure 1.

\section{General Discussion}

The approach adopted herein has a number of shortcomings which need to be fully understood when evaluating the data. When considering Figures 2-4 it is important to reflect on scheme size. There is no relationship whatsoever between the amount of content and the scheme quality. It is also not sound to assume that where content level is similar across schemes the potential benefits are similar in type or in significance. It is clearly not the level of content that is important but what it is actually addressing and promoting. In some instances, a small scheme can mean that the scheme 
objectives are narrow and the CPs are very direct and focused on this objective. Consequently, there may be very considerable benefits for policy but in only one policy area. In contrast, a large scheme may be very broad in the policy areas it covers, but the content may be shallow with respect to the details and this may be reflected in the potential policy benefits. It is important not to use the data to compare schemes because of differences in objectives, size and operation; like may not be compared with like even in the same sector.

There have been other studies that have aimed to review the UK assurance schemes. Many have focused on the role such schemes have in delivering specific outcomes, such as food safety (e.g. Northen, 2001; Hobbs et al., 2002; Mannings and Baines, 2004) or animal welfare (e.g. FAWC, 2001; Main et al., 2001; Veissier et al., 2008). Others have considered the role of the assurance schemes more generally. The most notable and recent of these is the study undertaken by Kirk-Wilson (2008) for the Food Standards Agency (FSA). The purpose of the Kirk-Wilson report was to assess how a range of assurance schemes had developed following a previous review again on behalf of the FSA (Kirk-Wilson, 2002). The earlier 2002 review concluded that the assurance schemes offered good potential to deliver a range of benefits to the consumer but raised concerns regarding the involvement of consumers and the transparency of consumer information. The 2008 report stated that there had been considerable improvements especially within the areas of setting standards, inspection and monitoring. The work reported herein is not a duplication of the FSA study as it specifically examined the potential of the assurance schemes to contribute to a range of environmental policy outcomes and standards with the requirements of EC food hygiene legislation. Work by consultants Levett-Therivel (2005) carried out for the Sustainable Development Commission (SDC) sought to identify if the schemes under the AFS umbrella could assure sustainable food production and consumption and so it does have similarities with that reported herein. The report concluded that the AFS schemes fell short of what was considered by the SDC as necessary for sustainable food production. With respect to both the 2006 FSA report and the Levett-Therivel report, the studies are based on standards that are now several years out of date and also policy objectives and desired outcomes have evolved during this time.

In the UK, an abundance of assurance schemes have emerged in the absence of central government intervention and the preference for the voluntary approach. Most developed countries have a legislated included a quantification of relevant content within the standards, whereas the objective of the Kirk-Wilson report was to assess how the schemes have developed since 2002. There are some minor overlaps particularly with respect to the review of operational procedures, but these are necessary in both studies for contextual purposes. Another FSA report (2006) only examined food safety issues and compared the system to protect consumers against poor quality food and, in general, the more stringent the regulation, the less need for assurance schemes. There is also a correlation between the stringency of such regulation and amount of environmental protection offered. Where regulation is rejected in favour of the voluntary approach, most developed countries will find alternative processes for delivering environmental policy usually via the provision of incentives such as farm payments and grants. For most developing countries, agriculture is vitally important for the national economy and there is little finance available for incentives aimed to protect the environment. Where living standards are poor, consumer values are more concerned with quantity rather than quality. Therefore, assurance schemes and their contribution towards national policy objectives will be of little interest to the consumer. However, there are strong desires to increase food exports as these are a major source of income. Compliance with assurance schemes will not only improve the confidence importers have in food safety and quality, but it may also have benefits for the local environment.

The study undertaken here began in late 2008. Most of the schemes regularly review their standards and update these to take account of, for example, changes in legislation or to reflect emerging best 
practice. Since this study, many of the primary production scheme standards considered have been revised and as such the results presented only show a snapshot of content at that time. A revisit of the current standards has shown that recent modifications (as of October 2009) are modest with no obvious increase or change in the focus of the standards relating to environmental protection and the findings of this study are, therefore, still valid.

\section{Conclusions}

It is important to be clear about the exact objective of this study so that there is no ambiguity or misinterpretation of the findings. The purpose was to evaluate a number of assurance schemes, to assess their content and the contribution they may be making towards a number of environmental policy outcomes. In assessing the relative performance of the schemes, the aim is not to criticize specific schemes for failing in particular areas but rather to understand the full spectrum of potential contributions that can be offered from the assurance scheme 'model' and how this fits within the government's need to improve the environmental impact of UK farming. It is fully recognized that the approach adopted has a number of shortcomings as previously discussed.

As mentioned previously, the analysis was not equivalent in any way to an environmental impact assessment nor did it attempt to evaluate potential outcomes. There are a wide range of techniques that could potentially be used for this including, for example, environmental risk mapping (Lahr, 2006), Life Cycle Assessment (RSC, 1998), Environmental Impact Assessment (Wood, 2003) and the use of environmental indicators (Hammond, et al., 1995). While many of these have been applied to agriculture (e.g. Bockstaller et al., 1997; Cederberg and Mattsson, 2000; Cederberg, 2002; Assimakopoulos et al., 2003; Brentrup et al., 2004; Christensen, 2006; Green et al., 2008), they have not previously been used to identify the contribution any individual activity makes towards an environmental outcome or for prioritizing activities in order to ensure maximum benefits are realized. Indeed, such techniques do not lend themselves easily to this task as it is a complex process of mapping specific farm activities to environmental impact outcomes. This work has been completed as part of thewider research project; however, the findings will be reported separately. The content analysis did not, therefore, provide precise detail quantifying the extent of policy benefits arising from the assurance schemes but this was not its aim. The results provide a first indication as to the coverage and, perhaps more importantly, identify gaps in content and thus where other delivery mechanisms are required to ensure policy objectives are realized. It is clear from the results that the mainstream schemes do not reflect the broad range of environmental care activities required by policy and it is debatable whether or not they are delivering on the expectations of consumers regarding environmental care. Therefore, it is believed that this first stage of the project has achieved its objectives.

Lewis et al. (2008) report that primary production standards have a variety of different goals ranging from the delivery of affordable safe, nutritious food to increased marketing opportunities or to address specific issues such as animal welfare. Assessing each of the schemes against their own objectives would undoubtedly have given a very different set of results to those presented here. None of the schemes considered were developed to address government policy objectives and many would argue it is not their role to do so, not least because of the costs and burdens that would be placed on farmers and growers if the remit of the schemes were to be broadened. However, the schemes are ideally placed to help the industry raise its standards and in the long term the alternative may be equally unpalatable if it results in greater government intervention.

\section{Acknowledgements}


This work has been funded by Defra as part of a wider research project. Defra's support is gratefully acknowledged. The opinions expressed herein are those of the authors and not necessarily those of the funding body. The authors wish to acknowledge the cooperation of both Tesco PIc and Jordan's Cereals in providing access to their standards and scheme documentation. The authors also express their gratitude to the independent specialist researcher who provided input into the content analysis.

\section{References}

ABM, 2008, Assured British Meat Beef and Lamb Farm Standards 2006, Version 6.1 (Implemented from 11 January 2008) [available at www.abm.org.uk], accessed Nov. 2008.

ABP, 2007, Assured British Pigs Certification Standards, Final Version August 2007.

ACCS, 2008, Assured Combinable Crops and Sugar Beet Scheme Standards, 2008-09 Final.

ACP, 2007, Assured Chicken Standards 2008-2009 for Breeder Replacement, Breeder Layers, Hatchery Chickens, Free Range, Poussin, Catching, Transport \& Slaughter, Including Operating Procedures, Revised December 2007 [available at www.assuredchicken.org.uk], accessed Nov. 2008.

ADF, 2008, Assured Dairy Farms Standards and Guidelines for Assessment, Edition 3.2, Issue 1 January 2008, Effective from 1 April 2008 [available at www.ndfas.org.uk], accessed Nov. 2008.

AP, 2008, Assured Produce Generic Crop Protocol Standards, Issue No. 1/2008 final [available at www. assuredproduce.co.uk/ap/scheme/about.aspx], accessed Nov. 2008.

Assimakopoulos, J. H., Kalivas, D. P., Kollias, V. J., 2003, 'A GIS based fuzzy classification for mapping the agricultural soils for $\mathrm{N}$-fertilizers use', Science of the Total Environment 309(1-3), 19-33.

Bauman, H., 1990, 'HACCP: Concept, development, and application', Food Technology 44(5), 156158.

Bockstaller, C., Girardin, P., van der Werf, H. M. G., 1997, 'Use of agro-ecological indicators for the evaluation of farming systems', European Journal of Agronomy 7(1-3), 261-270.

Brentrup, F., Ku“ sters, J., Kuhlmann, H., Lammel, J., 2004, 'Environmental impact assessment of agricultural production systems using the life cycle assessment methodology: I. Theoretical concept of a LCA method tailored to crop production', European Journal of Agronomy 20(3), 247-264.

Cederberg, C., 2002, 'Life cycle assessment (LCA) of animal production', PhD thesis, Department of Applied Environmental Science, Göteborg University, Sweden.

Cederberg, C., Mattsson, B., 2000, 'Life cycle assessment of milk production - a comparison of conventional and organic farming', Journal of Cleaner Production 8(1), 49-60.

Christensen, P., 2006, 'Danish experiences on EIA of livestock projects', Environmental Impact Assessment Review 26(5), 468-480.

Defra, 2002, The Strategy for Sustainable Farming and Food: Facing the Future, Defra Publications, London, Product code PB 7751A.

Defra, 2003a, Defra: Our Strategy 2003-2006, Defra Publications, London, Product code PB 7981.

Defra, 2003b, Air Quality Strategy for England, Scotland, Wales and Northern Ireland: Addendum, Defra Publications, London, Product code PB 7874.

Defra, 2004, Delivering the Essentials of Life: Defra's Five Year Strategy, The Stationery Office, Norwich, Product code PB 10303.

Defra, 2005, Securing the Future - UK Government Sustainable Development Strategy, The Stationery Office, Norwich, Product code PB 10589.

Defra, 2006a, Sustainable Farming and Food Strategy: Forward Look Supporting Economic and Statistical Analysis, Defra Publications, London.

Defra, 2006b, Pesticides and the Environment: A Strategy for the Sustainable Use of Plant Protection Products and Strategy Action Plans, Defra Publications, London, Product code PB 11721. 
Defra, 2007a, Air Quality Strategy for England, Scotland, Wales and Northern Ireland (Volumes 1 \& 2), The Stationery Office, Norwich, Product codes PB 12654 \& PB 12670.

Defra, 2007b, UK Biomass Strategy, Defra Publications, London.

FAWC, 2001, Interim Report on the Animal Welfare Implications of Farm Assurance Schemes, Defra, London, Product code PB5797.

FAWL, 2008, Farm Assured Welsh Livestock Beef and Lamb Scheme Producer Manual, Quality Welsh Food Certification Ltd, September.

FSA (Food Standards Agency), 2006, Assessment of Certain UK Farm Assurance Schemes Against the Requirements of the EC Food Hygiene Legislation, London, [available at www.food.gov.uk/multimedia/pdfs/assureschemeassess.pdf].

GCGP (The Guild of Conservation Grade Producers Ltd), 2007a, Guild of Conservation Grade Producers Ltd Conservation Grade Farming Protocol [available at www. conservationgrade.org/protocol.php].

GCGP, 2007b, Guild of Conservation Grade Producers Ltd Conservation Grade Farming Training Manual.

Genesis, 2007, Genesis Quality Assurance Limited Scheme Description and Regulations: Beef and Sheep Standards 2007/08, SF.063 issue 02; Pig Standards 2007/08, SF.063 issue 02; Arable and Sugar Beet Standards 2007/08, SF.063 issue 02, Genesis Quality Assurance Limited [available at www.genesisqa.com/consumers-info.asp],accessed Nov. 2008.

GlobalGap, 2007, Integrated Farm Assurance Control Points and Compliance Criteria. Modules for: All Farm Base, Livestock Base, Crop Base, Combinable Crops, Dairy, Fruit and Vegetables, Cattle \& Sheep, Pigs, Poultry, English versions, valid from 30 September 2007 [available at www.globalgap.org], accessed Nov. 2008.

Green, A., Lewis, K. A., Tzilivakis, J., 2008, FOOTPRINT: Creating Tools for Pesticide Risk Assessment and Management in Europe, The Association of Applied Biologists Conference, Pollution from Pesticides - Point Source versus Diffuse, Harper Adams University, Newport.

Hammond, A., Adriaanse, A., Rodenburg, E., Byrant, D., Woodward, R., 1995, Environmental Indicators: A Systematic Approach to Measuring and Reporting on Environmental Policy Performance in the Context of Sustainable Development, World Resources Institute,

Washington, DC. Hobbs, J. E., Fearne, A., Spriggs, J., 2002, 'Incentive structures for food safety and quality assurance: an international comparison', Food Control 13(2), 77-81.

Kirk-Wilson, R., 2002, Review of Food Assurance Schemes, Report for the Food Standards Agency, London.

Kirk-Wilson, R., 2008, Review of Uptake of FSA Food Assurance Scheme Guidance by UK Scheme Operators, Report for the Food Standards Agency, London.

Lahr, J., 2006, 'Spatial mapping of environmental risks: state-of-the-art and perspectives', Proceedings of the $1^{\text {st }}$ Open No Miracle Workshop, Verbania, Italy.

LEAF, 2007, Linking Environment and Farming LEAF Marque Global Standard 2008, LEAF, Warwick-

Shire. LEAF, 2008, LEAFwebsite - [available at

www.leafuk.org/leafuk/consumers/difference.aspx], accessed Nov. 2008.

Levett-Therivel Sustainability Consultants, 2005, Sustainability Implications of the Little Red Tractor Scheme, Report for the Sustainable Development Commission.

Levidow, L., 2000, "Euro-food: Pressures on R\&D, Policy Influences on Technology for Agriculture, Annex BII, TSER Programme, EU project number PL 97/1280.

Lewis, K. A., Tzilivakis, J., Green, A., Warner, D., Coles, A., 2008, 'Farm assurance schemes: can they improve farming standards?' British Food Journal 110(11), 1088-1105.

Main, D. C. J., Webster, A. J. F., Green, L. E., 2001, 'Animal welfare assessment in farm assurance schemes', Acta Agriculturae Scandinavica A 51(30), 108-113.

Mannings, L., Baines, R.N., 2004, 'Effective management of food safety and quality', British Food Journal, 106(8), 598-606. NIFQA, 2008, Northern Ireland Beef and Lamb Farm Quality 
Assurance [available at www.lovebeefandlamb.com/quality-guarantee/index.php], accessed Nov. 2008.

Northen, J. R., 2001, 'Using farm assurance schemes to signal food safety to multiple food retailers in the UK', International Review and Agribusiness, Management Review 4, 35-70.

QMS, 2007, Quality Meat Scotland: Cattle \& Sheep Standards Issue 7, updated September 2007; Pig Standards Issue 6, updated April 2007; Feed Standards Issue 10, updated July 2007; Haulage Standards Issue 6, updated July 2007 [available at www.qmscotland.co.uk/members/standards/cattle-and-sheep.html], accessed Nov. 2008.

RSC (Royal Society of Chemistry), 1998, Life Cycle Assessment, Health and Safety Committee, London.

Tesco, 2006, Tescos Nature's Choice Protocol and Code of Practice, November 2006, Issue 2, Tesco Stores Ltd.

Tesco, 2007. Tescos Nature's Choice Technical Guidelines 07,v02 March 2007, Tesco Stores Ltd. [available at www.tescofarming.com], accessed Nov. 2008.

Veissier, I., Butterworth, A., Bock, B., Roe, E., 2008, 'European approaches to ensure good animal welfare', Applied Animal Behaviour Science 113(4), 279-297.

Wood, C., 2003, Environmental Impact Assessment: A comparative review (2nd edn), Pearson Education Limited, England. 